\title{
Research on the Application of Big Data Statistics in the Field of Economic Management
}

\author{
Mingyu $\mathrm{Du}^{1}$ \\ ${ }^{1}$ Norwich school, Sichuan, China
}

\begin{abstract}
In the context of continuous social and economic development, the integration of statistics and economic management has been strengthened. Big data statistical technology has found economic development laws from many data, and its effect in macroeconomic analysis is extremely high. This article focuses on the application of big data statistical methods and existing problems in the field of economic management and proposes corresponding countermeasures.
\end{abstract}

\section{INTRODUCTION}

Statistics is to find the law of value implicit in the data by collecting data and adopting measurement methods, and then apply it to a discipline in other fields. With the continuous innovation and improvement of data mining technology and statistical analysis methods, based on the increasingly severe pressure of economic market competition, the comprehensive implementation of statistics in economic management can provide a good basis for the improvement of management efficiency and the allocation of resources. Therefore, it is necessary to strengthen the application of big data statistical analysis methods in the field of economic management [1].

\section{BIG DATA STATISTICS IS AN INEVITABLE REQUIREMENT OF ECONOMIC AND SOCIAL DEVELOPMENT IN THE NEW PERIOD}

The so-called big data mainly refers to the integration of data. When the previous software is used to work in the corresponding time, the data cannot be processed reasonably, but the process is optimized in a reasonable way to improve decision-making power. And massive information resources. For big data technology, is not only to grasp a lot of data information, but also to deal with the data professionally. Among them, from a technical point of view, there is a direct connection between big data and cloud computing, but it is impossible to reasonably process big data with a single computer. These are inseparable from the help of distributed architecture [2]. Data, work with the help of virtualization, cloud storage and other technologies. Big data itself has the characteristics of authenticity and high speed.

In the context of continuous improvement and optimization of information technology, big data statistics are widely used and valued in various fields. From the perspective of macroeconomic forecasting, business management, marketing and risk forecasting, the big data statistical analysis method has a very high application effect. This method can not only optimize the business structure of the enterprise, improve management efficiency, but also enhance the overall strength of the enterprise. Provide sufficient motivation for employee development, and promote enterprises to stand out in the fierce market competition

\subsection{Promote new industries and promote the reorganization and upgrading of the original industrial structure}

Science and technology are the primary productive forces, and the development of big data has further promoted the innovation of the industry and expanded the space for growth and development of emerging industries. Actively nurture the big data industry in emerging strategic industries. Through data sharing and data analysis, focusing on relevant decision-making, forecasting, data outsourcing leasing services, and development and application will effectively promote data pharmaceutical, data materials, data services, and data chemistry And other emerging industries. In this way, development and application in traditional manufacturing, tourism, transportation, environmental protection, medical and health industries are conducive to promoting product upgrades and continuous optimization of the industrial structure [3]. "

\subsection{Can promote the government's macro management and corporate economic benefits}

In some specific fields, big data statistical analysis can predict the future economic development trend. The big data statistical analysis work is handled by the data model, and the macroeconomic development rules can be clarified with the help of informatization. Therefore, the 
introduction of the big data analysis method provides a fixed basis for the macroeconomic analysis. The application of big data statistics can truly reflect the economic development, especially in the analysis of social and economic operations [4]. The government can draw more objective conclusions through the results of statistical analysis of big data, thereby helping the government to carry out macro-control, and effectively promoting the progress of government services and industries. Through the use of digital methods, companies find statistical methods that are consistent with their own characteristics, conduct in-depth analysis of the market to obtain accurate market positioning, use big data platforms to analyze industrial economy, and make timely adjustments to product structure. Big data statistics not only help enterprises to carry out accurate marketing and operation, but also help enterprises to carry out classified management and clearly recognize their own weaknesses, so as to enhance their ability to resist risks [5].

At this stage, market competition is becoming increasingly fierce. On the one hand, foreign companies have a huge impact on domestic companies under the background of economic globalization; on the other hand, domestic market competition is becoming increasingly fierce. Optimize production and operation methods to provide accurate information for the adjustment of corporate strategy. Increasingly complex business operations, finances and risks, and human resource management methods require statistical analysis to sort and summarize. The use of traditional human data collection and sorting methods, in addition to increasing cost output, has low work efficiency and There are many limitations. In the context of computer Internet technology, these tedious and complex tasks can be carried out in the network data platform, achieving the goal of saving time and effort and high accuracy. In addition, it provides convenience for communication between various departments of the enterprise, and employee performance evaluation can also obtain relevant information from it, which provides a certain basis for selecting cadres and appointing talents. All in all, under the background of continuous improvement and innovation of science and technology, various types of network platforms have been widely popularized. In the past, single work methods were abandoned, and work efficiency has been significantly improved.

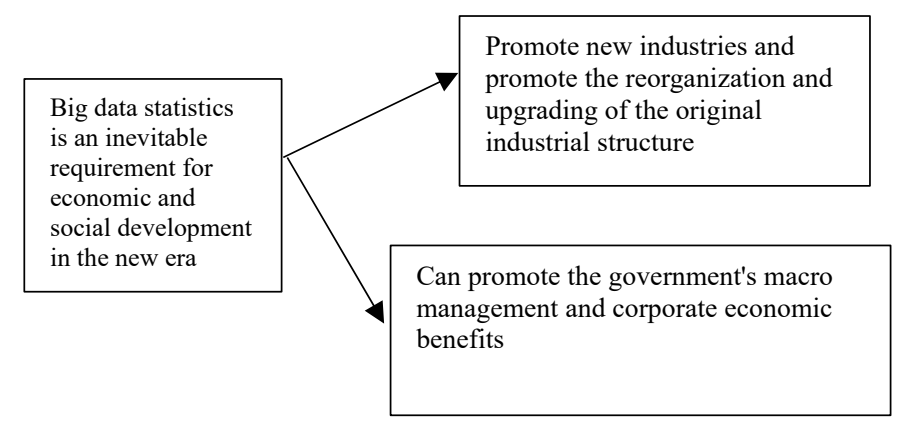

Figure.1 Big data statistics is an inevitable requirement for economic and social development in the new era

\section{ACTUAL APPLICATION OF BIG DATA STATISTICS IN THE FIELD OF ECONOMIC MANAGEMENT}

\subsection{Classified management database and construction of big data economic model}

In the field of economic management, the characteristics and functions of different industries are different. To reflect the effect of economic management, it is necessary to apply the big data technology reasonably to the relevant departments of our country, combining the characteristics of different industries to build The corresponding economic management classification database is open to the relevant objects. After the creation of the classification database is completed, no matter whether it is an enterprise or a country, the economic management layer can search the data in the industry database by way of authority to achieve the goal of economic management and improve the efficiency of big data applications. Based on the role of big data in economic management, when creating a classification database, one must also understand the characteristics of the Internet. Because the database is open to the outside world, the security of data information must be guaranteed. Therefore, it is necessary to strengthen the construction of security systems and do a good job of data backup management to avoid damage due to the invasion of diseases and viruses.

In the field of economic management, whether it is macro-control at the national level or economic management during the production and operation of enterprises, in the process of decision-making, different types of data should be used, and the results should be used as the main basis. Therefore, when applying big data statistical technology, you can combine computer software and big data information acquisition technology to build a big data economic model, adjust the data information in the model according to market development, and keep abreast of future changes in the market. Predict possible change trends, thereby optimizing economic management methods and improving economic management benefits.

\subsection{Application in enterprise human resource management}

Human resources are the main support for enterprise development, and effective human support is the driving force for enterprise development. By adopting big data statistical analysis technology, personnel can be selected 
according to the fundamental demand for talents, so as not to consume too many talents from the massive resumes. More time and energy. Moreover, the big data analysis technology can also analyze the human resource needs of the company according to the actual requirements and future trends of the enterprise, and apply regression statistical methods, dynamic analysis and forecasting methods to understand the changes in the human resources of the enterprise, etc. The business is running well.

\subsection{Application in enterprise risk management}

During the operation and management of the enterprise, the statistical analysis method is used to classify and collect various information during the operation period, and find specific laws and data anomalies. This is positive for the management to make decisions, respond to various problems, and solve business risk problems. effect. Due to the corresponding regularity of business operations, when conducting statistical analysis of data, enterprise management personnel must pay close attention to the abnormal phenomena and analyze the substantive causes of abnormal phenomena, especially in the area of financial management, do a good job of statistics of corporate financial information Analysis is the main way to avoid risks.

\subsection{Application in enterprise financial management}

The big data statistical analysis method is applied to the financial management of the enterprise. By analyzing the various data during the production and operation period, the enterprise is conducive to the further development of the enterprise's investment work. Financial management is an indispensable link during the operation of an enterprise. It is a key point to reduce the probability of risk and optimize enterprise resources. The financial data after statistical analysis can provide accurate decision information for enterprise managers and decision makers.

\subsection{Application of enterprise marketing management}

There are differences between different industries. Whether it is in the food field or other industrial fields, the business philosophy and economic structure that they uphold are different, and these can be highlighted in corporate marketing management. Among them, the actual consumer demand of consumers determines the business direction of various fields. In other words, enterprises need to adjust product characteristics or product positioning according to the basic requirements of consumers. This is to optimize production structure and functional commodities to attract many consumers. The substantive reason of the person. By applying big data statistical analysis technology, enterprises can clearly grasp and understand consumer needs in this field, dynamically analyze social and economic conditions, transform products with low sales volume, improve product taste, and meet the diversified requirements of consumers.

\subsection{Analysis of problems in the application of economic management}

The big data innovation awareness is not strong and the management concept of the enterprise is relatively backward. In the process of economic development, some local government departments often have a situation that emphasizes management over services, government over society, and local oversight. They have little awareness of big data applications, and they have no strategy to raise big data development innovation to a certain degree. High; while some companies lack a comprehensive understanding of the importance of big data construction, in the process of decision-making, they often adopt traditional corporate management concepts, and traditional management concepts cannot predict the possible change trends in advance, so they cannot Improve economic management efficiency. The existing basic conditions for the application of big data are imperfect, and they cannot meet the requirements of big data innovation and development in terms of policy research, technology, capital, and human investment. The big data innovation and development lack a strong guarantee.

The development level of big data innovation technology is not high. For big data, data analysis is the core. In the process of business management, it is important to use statistical analysis methods to classify and collect various information and find specific laws and data anomalies, which are very important for business managers to make decisions, deal with various problems and solve business risk problems. effect. The current big data processing technology foundation is relatively weak, the development of technology and analysis technology are not balanced, there is a serious lack of in-depth mining and systematic analysis of big data systems, there is a serious lack of innovation in application models, and the risk awareness is not strong. It is difficult to meet the specific needs of big data. Lack of original technology, blindly copying the current experience in the specific practice process, resulting in inability to adapt to specific situations.

There is a shortage of big data innovators. The shortage of big data innovation personnel has resulted in poor integration of big data technology development and social development. Enterprise managers lack a certain sense of innovation, lack of big data development vision and training of comprehensive technical personnel, so they cannot meet the needs of social and economic development. .

There is no scientific management system for big data statistics. At present, there is no scientific management system for big data statistics, which can not provide scientific decision-making basis for government and enterprises. Big data statistics cannot play its real role in the field of economic management.

Big data statistics cannot fully adapt to various industries. In the field of economic management, there are certain differences in various industries. Big data statistics and in-depth research and analysis are required for each industry. However, due to the historical factors and the nature of certain industries, big data statistics cannot be studied and analyzed. 


\section{Big Data Statistical Methods In The FieLd Of ECONOMIC MANAGEMENT}

The important role of big data is now recognized by most governments and international organizations, and the development and utilization of big data has been regarded as a key factor to strengthen national competitiveness and seize the commanding heights of a new round of competition. At present, China's big data industry is in a period of rapid development With the continuous popularization of the Internet and the continuous development of the Internet of Things technology, the future market size will continue to expand. Therefore, big data research and production plans have been raised to the national strategic level, and deep research on the statistical methods of big data in economic management Application is extremely important.

Change and optimize management concepts. To reflect the use of big data statistical technology, for enterprises, it is necessary to transform and optimize the company's management philosophy, and effectively apply big data statistical analysis technology to economic management. Based on this, when an enterprise conducts business management, it is necessary to establish a correct statistical analysis thinking concept, abandon the previous single way of thinking, enhance data information thinking and awareness, recognize the role of big data in enterprise development, and enable enterprise managers Transform Internet thinking concepts with employees and create a good environment conducive to the development of the enterprise.

Formulate a sound and complete big data management work system. In the field of economic management, enterprises need to improve the big data management work system. First, focusing on information collection, integration and feedback systems, analyzing and mastering various data during the work period, do a good job in the feedback of various problems during the operation period, develop an information early warning system, and carry out information on abnormal conditions. Early warning processing to avoid hindering the operation of the enterprise. In addition, in order to cope with the abnormal phenomena found in the statistical results of big data, a data and management emergency system should be created. Its purpose is to adjust the management and management of the enterprise according to the accurate data analysis results, and accurately analyze the main causes of the problems to Suppress the problems that hinder the normal operation of the enterprise.

Improve the qualities and work skills of relevant personnel. In the usual training, in addition to deepening the employees' knowledge of economic theory, it is also necessary to vigorously improve the management level of employees so that they can correctly understand the advantages of big data. Do a good job in computer skills training to enable employees to master big data statistics and management frameworks and application points in all aspects to ensure greater advantages in their work.

Make scientific and reasonable economic decisions with the help of big data statistics. Applying big data statistical methods to economic management can enable decision-makers, especially grassroots workers, to understand and discover problems more quickly, put forward relevant suggestions, and improve the timeliness of economic management. When applying big data statistical technology, for economic management decisionmaking, data collection and analysis methods gradually replace the traditional intuitive and empirical decisionmaking methods, which can reduce the probability of decision-making risk.

\section{CONCLUSION}

Increase control over data analysis. In the new era, China has gradually stepped up its efforts to modernize its economy and clearly understand the role of big data technology. Based on a long-term perspective, in the process of strengthening economic management in China, it is necessary to dynamically reflect the processing and analysis functions of big data technology. Only accurate and reasonable analysis and integration of various data can further improve economic management. Scientific and targeted. During the economic management work, diversified data collection and collation should be the mainstay. In the process of comprehensive application of big data statistical technology, diversified data should be transmitted to the data platform, and then a reasonable economic management plan should be formulated according to the actual situation. Implement various economic management decision-making methods to supervise and forecast various data, and adjust economic management measures to provide guarantee for economic management decision-making. Due to the impact of economic transformation, the company's previous management model clearly does not meet the current development requirements of the company. The application of big data statistics technology can not only ensure the company to obtain accurate information, but also provide certain power and good development opportunities for the company's development, it can clearly analyze and explore the basic needs and potential risks of the market, carry out risk prediction and risk assessment of the market. Only by understanding and clarifying the risks as early as possible and formulating timely response measures can the probability of damage to the enterprise be reduced.

\section{REFERENCES}

1. Jiang Hongmei. How to use big data statistics in the field of economic management [J]. Chinese and foreign entrepreneurs, 2019 (27): 52.

2. Du Min. Analysis of the application of big data statistical analysis methods in the field of economic management [J]. Shanxi Agricultural Economics, 2019 (12): 27.

3. Chen Xueqin. The application of big data statistical analysis method in the field of economic management [J]. Shanxi Agricultural Economics, 2019 (5): 37.

4. Zhu Huaiqing. The impact of big data era on statistics teaching of undergraduate economics and 
management and countermeasures [J]. Higher Education Research (Chengdu), 2014, 031 (003): P.35-37.

5. Liu Surong. Research on Teaching Reform of Statistics Course of Economics and Management Major under Big Data Thinking [J]. Journal of Higher Education, 2018, 000 (010): 131-133,136. 